\title{
Toxic and essential metals in placenta and its relation with lipid peroxides/glutathione status in pre-term and full-term deliveries
}

\author{
Laxmi Singh, Priyanka Agarwal, Madhu Anand and Ajay Taneja \\ Department of Chemistry, Dr. B.R.Ambedkar University, Khandari Campus, Agra-282002, India
}

\section{A B S T R A C T}

\begin{abstract}
Aims and Objectives: Pre-term birth is worldwide problem, little is known about oxidative stress in placental tissue due to metals exposure of women during pregnancy. To seek correlation between concentration of metals and redox status in placental tissue of women with pre-term delivery and compared with those of women with the full-term delivery. Materials and Methods: A hospital based case-control study was conducted, total 80 pregnant women were selected for this study i.e., 30 females who delivered pre-term babies (gestational age $<37$ week) serve as study group and 50 females who delivered full term babies (gestational age $>37$ week) serve as control group. Concentrations of metals lead $(\mathrm{Pb})$, cadmium $(\mathrm{Cd})$, iron ( $\mathrm{Fe})$, zinc $(\mathrm{Zn})$, and $(\mathrm{Cu})$, malondialdehyde (MDA) end product of lipid peroxidation and glutathione (GSH) were measured in placenta of study group and control group. Data were analyzed using Students t- test, chi square and linear regression. Results: In preterm cases level of malondialdehyde (MDA) and metals ( $\mathrm{Cd}$ and $\mathrm{Pb}$ ) were significantly higher, while level of GSH and some metals ( $\mathrm{Fe}, \mathrm{Zn}$ and $\mathrm{Cu}$ ) were significantly lower in pre-term cases when compared to full-term cases. There were significant positive correlations of placental metals ( $\mathrm{Pb}$ and $\mathrm{Cd}$ ) with MDA $(\mathrm{p}<0.05)$, suggests that metals might have influenced pre-term deliveries. Conclusions: The results showed that elevated level of placental $\mathrm{Cd}$ and $\mathrm{Pb}$ induced oxidative stress which might implicate in pre-term deliveries and higher concentration of $\mathrm{Zn}$ and $\mathrm{Cu}$ may be concerned with the defence against oxidative stress in placental tissue of full-term cases.
\end{abstract}

Access this article online Website:

http://nepjol.info/index.php/AJMS DOI: 10.3126/ajms.v7i1.12808

Key words: Pre-term birth, Placental tissue, Oxidative Stress, Metals

\section{INTRODUCTION}

Gestational age of a neonatal which calculated from the last menstrual period is before 37 completed weeks is a pre-term. According to World Health Organization (WHO) report 2012, India has maximum number of preterm delivery cases followed by China and top of the list in the world. ${ }^{1}$ Pre-term delivery is responsible for $70 \%$ of mortality and $75 \%$ of morbidity in the neonatal period, especially in industrialized countries. In Agra region premature birth (33.6\%) and LBW (low birth weight) are two major factors for high neonatal mortality. ${ }^{2}$ We selected Agra city for this study because it has more than 13 larger and 7200 Small Scale Industrial Units (SSIU) in the district, these industries are responsible for highly polluted environment. ${ }^{3}$ During the pregnancy women are exposed to a wide variety of foreign chemicals including metals through maternal medication, lifestyle factors (smoking, drug abuse, alcohol consumption), occupational and environmental sources and other risk factors such as socioeconomic status, race/ ethnicity and domestic smoke (as from burning of biomass fuel for cooking). ${ }^{4}$ These metals readily move across the placental barrier. Placenta serves as an intermediary and binds two genetically distinct individuals, the mother and the fetus. ${ }^{5}$ In addition, accumulation of these metals in placenta, may affect the normal placental function, consequently upsetting the fetal development and lastly, at the terminal phase of placental life, i.e., delivery. ${ }^{6}$ Many 
studies suggest association between toxic/essential metals in the placenta and premature birth, while some metals such as copper $(\mathrm{Cu})$, zinc $(\mathrm{Zn})$ and iron $(\mathrm{Fe})$ are essential nutrients required for normal pregnancy and intrauterine growth but $\mathrm{Pb}$ and $\mathrm{Cd}$ are highly toxic at low concentration, could affect fetal growth and gestational age. Excess or deficiency of crucial metals during pregnancy is closely related to mortality and morbidity in the new born, preterm and chronic metabolic disturbances. ${ }^{7}$

On the other hand, during pregnancy placenta is mostly mitochondria rich. This condition favours oxidative stress, which may also be enhanced by the addition to enzymatic activity and toxicity of metals capable of generate reactive free radicals. These free radicals interact with nuclear proteins, causing oxidative deterioration of lipid bilayer. As mentioned previously, oxidative stress has been associated with early deliveries as well as preeclampsia and trigger reduction of placental blood flow, which may even lead to fetal death. ${ }^{8}$ Formation of Free radical increases during normal pregnancy, since increased cell turn-over or decreased antioxidants defence mechanisms; but source of reactive free radical in pre-term is not fully understood. ${ }^{9}$ Excessive amount of ROS production during pregnancy, however, may overpower the antioxidant defence system. Deficiencies of specific antioxidant activities associated with the micronutrients copper and zinc. Results regarding decreased antioxidants defence activities implicated with poor pregnancy outcomes and the associated increased risk of diseases in adulthood, including cardiovascular disease and type 2-diabetes. This unwanted condition may be a consequence of an imbalance between toxic and essential metals in favour of the former during normal pregnancy. The effect of placental oxidative stress is controlled by the interception, modification and destruction of ROS through the action of endogenous antioxidants proteins including glutathione peroxidise enzymes and copper/ zinc-dependent superoxide dismutase (Cu/Zn- SOD). Antioxidants require $\mathrm{Zn}$ and $\mathrm{Cu}$ as cofactors enzymes and protect the fetus. Although reduced activities of some antioxidants enzymes are associated with increased ROS, may be implicated with pre-term deliveries. ${ }^{10}$ In view of these observations, we therefore, designed this present case-control study to evaluate the association between level of metals $(\mathrm{Cd}, \mathrm{Pb}, \mathrm{Zn}, \mathrm{Cu}$ and $\mathrm{Fe}$ ) exposure, with oxidative stress/antioxidant in the females who delivered pre-term or full-term babies, residing in Agra city area northern part of India.

\section{MATERIALS AND METHODS}

Present study is based on the results from 80 pregnant women (30 pregnant women who had gestational age
$<37$ weeks and 50 pregnant women with $>37$ weeks) whose placenta were analyzed for metal concentrations with oxidative stress in terms of lipid-peroxidation and glutathione. These pregnant women were selected from the Department of Gynaecology S.N. Medical College, Agra. Total 180 participants were enrolled in this study, out of them 80 women were excluded due to incomplete data, misplaced samples and questionnaires, 20 participants had changed hospital for delivery therefore could not collect samples. Placental tissues were taken from healthy pregnant women, after 28 weeks of gestational age after delivery. We took trophoblastic part of placenta tissue without sign of calcification, avoiding the decidua basalis and chorionic plate in accordance with recent study. ${ }^{11}$ Placental tissues were collected during parturition. Approximately $25 \mathrm{gm}$ of placental tissue taken from each subject were collected in wide-mouthed containers as coded samples; in an ice container for metals analysis and other biochemical assays. According to declaration of Helsinki all the pregnant women had given informed written consent and were personal interviewed after delivery as ascertain maternal age, weight and height, parity, residence area, source of drinking water, smoking habits, dietary, addiction habit, literacy, duration of lactation, used fuel for cooking, haemoglobin and reproductive history. In each case, data about maternal status and outcomes of birth were provided by gynaecology department of S. N Medical College Agra, India. The study sample population was rather homogeneous in terms of the socioeconomic status, age and nutrition habits.

A portion of placental tissues was used for preparation of homogenate $(10 \%, \mathrm{w} / \mathrm{v})$. Briefly, all placental tissues were washed carefully three times with ice cold physiological saline water, dried on filter paper, and homogenized in phosphate buffer saline (PBS) using homogenizer. An aliquot of homogenate used for determination of malondialdehyde (MDA) last product of lipid peroxidation by method of Ohkawa et al., $(1979)^{12}$ and spectrophotometrically evaluated at $412 \mathrm{~nm}$. Remaining portion of homogenate was centrifuged for $30 \mathrm{~min}$ at $4000 \mathrm{rpm}$ and supernatant (placental extract) was collected for determination of glutathione (GSH) by using Ellman (1959) method $^{13}$ and the absorbance finally measured at $530 \mathrm{~nm}$. Remaining placentas were frozen at $-4^{\circ} \mathrm{C}$ immediately until selective metals analysis. Special care taken in maintaining the ice-cold chain from the site of collection to the site of processing and all the biochemical parameters were assayed on the same day. For extraction of metals, $1.0 \mathrm{gm}$ of placental tissue in a $50 \mathrm{ml}$ Erlenmeyer flask was digested at $120^{\circ} \mathrm{C}-150^{\circ} \mathrm{C}$ with concentrated nitric acid till a clear solution was obtained. This solution was quantitatively transferred to a $10 \mathrm{ml}$ volumetric flask and made up to volume with deionized 
water. A blank sample was also prepared with each set of samples in order to control possible metal contamination by external sources. Additionally, a quality check sample was always run with each set of samples for lead analysis to maintain accuracy. ${ }^{14}$ Placental level of metals $(\mathrm{Pb}, \mathrm{Cd}, \mathrm{Fe}$, $\mathrm{Zn}$ and $\mathrm{Cu}$ ) were analysed by ICP-MS (Inductive Coupled Plasma- Mass Spectrophotometer) (Element XR, thermo Fisher Scientific, Germany).

Data were analysed statistically using IBM-SPSS (version-22) and the linear regression was used to determine the strength of relationship between placental metal concentrations with oxidative parameters. We used Chi square and Students- t-test for the association between categorical and continuous variables, respectively (Table 2). A p-value less than 0.05 was accepted as statistically significant. Results were reported as mean \pm SD.

\section{RESULTS}

The characteristics (such as age, weight, BMI, drinking water supply and area of residence) of females with fullterm or pre-term deliveries that were recorded in this study are shown in Table 1 . No statistically significant differences were observed in maternal age, weights, height, number of children, duration of lactation and BMI (Body mass index) between two groups. However, there was significant difference in blood haemoglobin $(\mathrm{p}<0.001)$. Concentrations of metals $(\mathrm{Cd}, \mathrm{Pb}, \mathrm{Fe}, \mathrm{Cu}$ and $\mathrm{Zn})$ in placental tissue with full-term and pre-term cases are shown in Table 2. The level of GSH $(p<0.05)$ was found significantly increased in full-term groups $(p<0.05)$ when compared to pre-term group, whereas, placental MDA level was significantly higher in pre-term group when compared with full-term group $(\mathrm{p}<0.001)$ (Figure $1 \mathrm{a}$ and $\mathrm{b}) . \mathrm{Pb}$ and $\mathrm{Cd}$ levels were higher in pre-term group while $\mathrm{Fe}, \mathrm{Zn}$ and $\mathrm{Cu}$ levels were higher in the full-term group but difference were not found statistically significant in $\mathrm{Fe}, \mathrm{Zn}$ and $\mathrm{Cu}$, only $\mathrm{Pb}$ and $\mathrm{Cd}$ were found significantly higher in preterm cases. Figure 2, and 3 depicts the strength of relationship between MDA and placental $\mathrm{Cd}\left(\mathrm{R}^{2}=0.05, \mathrm{p}<0.05\right)$ and $\mathrm{Pb}\left(\mathrm{R}^{2}=0.05, \mathrm{p}<0.05\right)$. There was signsificantly negative correlation of placental $\mathrm{Pb}$ levels with GSH $\left(\mathrm{R}^{2}=0.05\right.$, $\mathrm{p}<0.05)$ (Figure 4).

\section{DISCUSSION}

Pre-term birth is complex and unresolved public health problem but cause of these problems is surely complex and unknown. There are number of factors responsible for preterm delivery, but it now appears that oxidative stress in trophoblastic placental tissue may play a crucial role. The generation of free radical in the human placenta

\begin{tabular}{|c|c|c|}
\hline Variables & $\begin{array}{c}\text { Pre-term } \\
(n=30)\end{array}$ & $\begin{array}{l}\text { Full-term } \\
(n=50)\end{array}$ \\
\hline Age of mother (years) & $24.63 \pm 3.10$ & $25.54 \pm 3.87$ \\
\hline Height $(\mathrm{cm})$ & $154.32 \pm 3.66$ & $155.11 \pm 5.30$ \\
\hline Weight (kg) & $56.95 \pm 3.01$ & $58.78 \pm 7.14$ \\
\hline BMI $\left(\mathrm{kg} / \mathrm{m}^{2}\right)$ & $23.96 \pm 2.96$ & $24.50 \pm 2.71$ \\
\hline No. of children & $1.76 \pm 0.95$ & $1.44 \pm 0.75$ \\
\hline Haemoglobin $(\mathrm{g} / \mathrm{dl})^{*}$ & $8.15 \pm 1.10$ & $9.88 \pm 0.866$ \\
\hline Duration of lactation (months) & $15.1 \pm 8.76$ & $11.5 \pm 8.96$ \\
\hline \multicolumn{3}{|l|}{ Abode } \\
\hline Urban & $36.66 \%(11)$ & $62 \%(31)$ \\
\hline Rural & $63.33 \%(19)$ & $38 \%(19)$ \\
\hline \multicolumn{3}{|l|}{ Addiction (Smoking habit) } \\
\hline Yes & $56.66 \%(17)$ & $52 \%(26)$ \\
\hline No & $43.33 \%(13)$ & $48 \%(24)$ \\
\hline \multicolumn{3}{|l|}{ Dietary habit } \\
\hline Vegetarian & $73.33 \%(22)$ & $62 \%(31)$ \\
\hline Nonvegetarian & $26.66 \%(8)$ & $38 \%(19)$ \\
\hline \multicolumn{3}{|l|}{ Source of drinking water } \\
\hline Private & $66.66 \%(20)$ & $56 \%(28)$ \\
\hline Government & $33.33 \%(10)$ & $44 \%(22)$ \\
\hline \multicolumn{3}{|l|}{ Literacy } \\
\hline Below $10^{\text {th }}$ & $60 \%(18)$ & $60 \%(30)$ \\
\hline Above $10^{\text {th }}$ & $40 \%(12)$ & $40 \%(20)$ \\
\hline \multicolumn{3}{|l|}{ Used fuel for cooking } \\
\hline LPG & $36.66 \%(11)$ & $70 \%(35)$ \\
\hline Biomass fuel & $63.33 \%(19)$ & $30 \%(15)$ \\
\hline
\end{tabular}

\begin{tabular}{|c|c|c|}
\hline Metals concentration & Pre-term $(n=30)$ & Full-term $(n=50)$ \\
\hline $\mathrm{Pb}^{*}$ & $3.86 \pm 1.08$ & $2.00 \pm 2.05$ \\
\hline $\mathrm{Cd}^{*}$ & $0.626 \pm 0.729$ & $0.187 \pm 0.264$ \\
\hline $\mathrm{Fe}$ & $50.60 \pm 41.52$ & $58.94 \pm 38.42$ \\
\hline $\mathrm{Cu}$ & $0.220 \pm 0.116$ & $0.255 \pm 0.430$ \\
\hline $\mathrm{Zn}$ & $17.26 \pm 13.68$ & $18.28 \pm 14.36$ \\
\hline
\end{tabular}

can occur as in other tissues. ${ }^{15}$ Previous studies have demonstrated an increase in MDA and decrease in GSH in placental tissue lead to preterm. ${ }^{9}$ Our data shows, similar results in pre-term groups, MDA level was significantly higher $(\mathrm{p}<0.05)$ while GSH level was significantly lower $(\mathrm{p}<0.05)$ in placental tissue of women with the pre-term delivery compared to women with the full-term delivery (Figure 1 a). Increased MDA and decreased GSH level in pre-term than full-term cases indicate diminished ability to resist oxidative damage and associated with an imbalance between oxidative parameters; ${ }^{16}$ Increased MDA is indirectly proportional to gestational age. Decreased level of GSH in IUGR (intra uterine growth retardation) and preterm placentas in comparison with the control group has been determined ${ }^{17}$ similar to our study. Level of serum MDA was significantly higher in preterm deliveries as compare to full term deliveries in both maternal and cord 


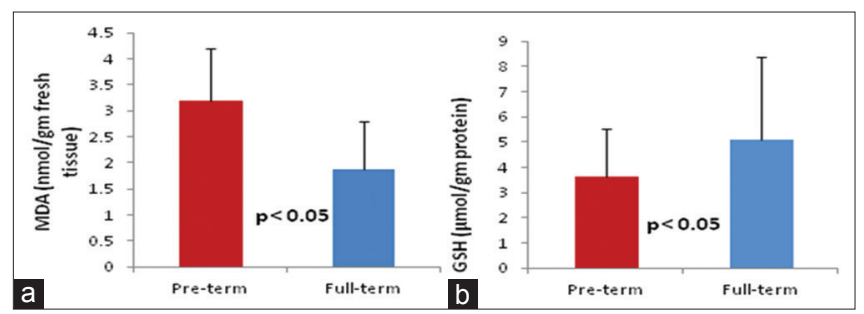

Figure 1: (a) Comparsion of levels of MDA in pre-term and full-term delivery cases. (b) Comparsion of levels of GSH in pre-term and fullterm delivery cases

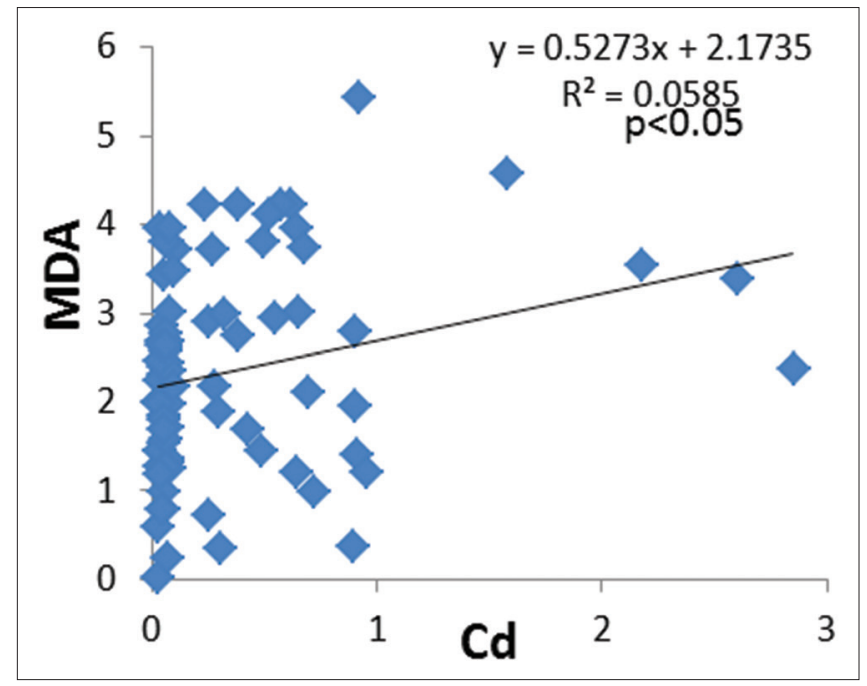

Figure 2: Placental MDA level plotted against placental Cd

blood was also reported in earlier study. ${ }^{18}$

Our findings are consistent with previous studies suggesting that MDA is an important factor in the pre-term delivery. The significant positive correlation in placental $\mathrm{Cd}$ and $\mathrm{Pb}$ with MDA (Figure 2 and 3) suggests that $\mathrm{Pb}$ and $\mathrm{Cd}$ may be associated with increased formation of ROS and thus produce oxidative stress in pregnant women. $\mathrm{Cd}$ and $\mathrm{Pb}$ are a strong inducer of oxidative stress in the placenta tissue, mainly through inhibition of antioxidant enzymes such as glutathione (GSH) has been reported by many researchers. ${ }^{19,20}$ In the present study, placental $\mathrm{Cd}$ and $\mathrm{Pb}$ levels were significantly higher in women with preterm deliveries as compared to the full-term delivery, which is supported by previous study, shown significantly higher placental $\mathrm{Pb}$ level in the cases of preterm delivery and premature rupture of membranes than those of the full-term. ${ }^{21}$ Levels of oxidative stress parameters were significantly higher in women with preterm babies than full-term babies have been determined, ${ }^{22}$ while role of $\mathrm{Cd}$ is not clear in oxidative stress. However, indirectly, $\mathrm{Cd}$ induces oxidative stress by a displacement of redox-active metals, inhibition of anti-oxidant enzymes and resulting in mitochondrial damage. ${ }^{23}$ In our study, concentration of $\mathrm{Cd}$ found 1.5 times elevated in rural areas women when

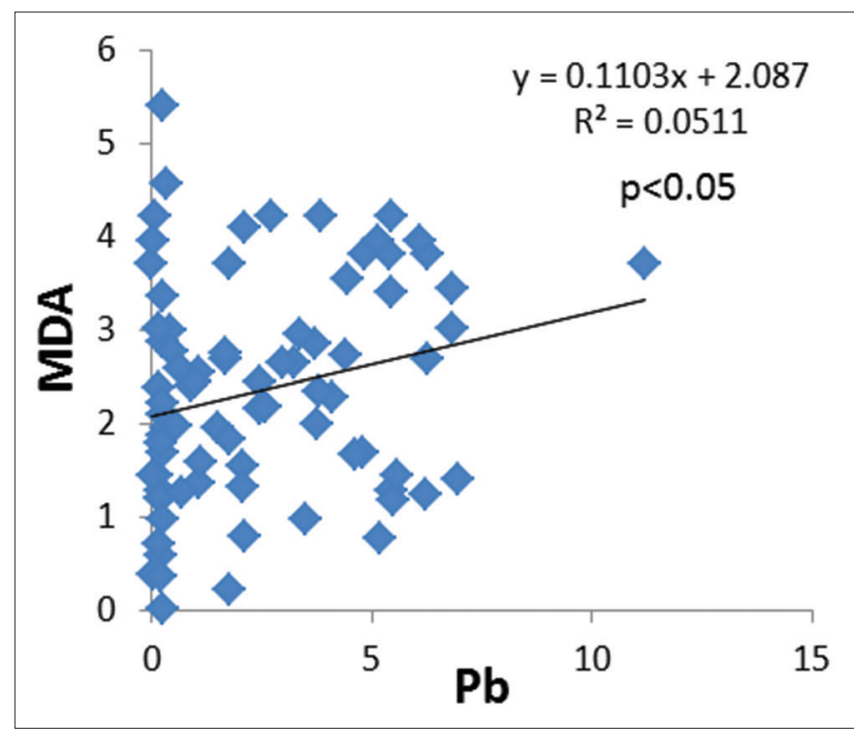

Figure 3: Placental MDA level plotted against placental Pb

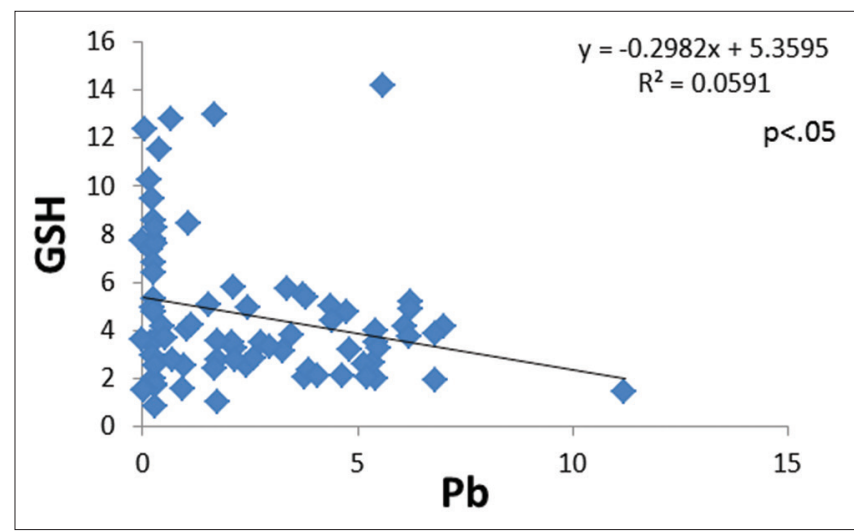

Figure 4: Placental GSH level plotted against placental Pb

compared to urban areas women is agreement of previous study, has found higher level of $\mathrm{Cd}$ in placental tissue of rural areas women. ${ }^{24}$ Level of placental Cd was found 3.4 times higher in women who used biomass fuel for cooking than women who used LPG (Liquid Petroleum Gas) for cooking purpose. Biomass fuel combustion are sources of metals such as $\mathrm{Cd}$ and $\mathrm{Pd}$ in indoor has been reported in many studies and especially women are exposed to these metals because they spend on the average 5-6 hours per day near stoves in the kitchen. ${ }^{25}$

Moreover, in the present investigation, placental $\mathrm{Cd}$ and $\mathrm{Pb}$ had significant positive correlations with MDA provoked oxidative stress and suggests increased oxidative stress leading to increased rate of lipid peroxidation in preterm deliveries which may be contributed in prematurity and its complications, whereas negative correlation between placental Pb and GSH (Figure 4) indicating lead-induced disruption of oxidant/antioxidant balance in the placenta of women having preterm deliveries. These data are similar to the only published Indian study which shows that $\mathrm{Pb}$ 
induces oxidative stress among pre-term cases, residing in around Lucknow. ${ }^{26}$

The effects of reactive oxygen species (ROS) are maintained by antioxidants such as GSH, mechanisms against effects of oxidative stress are constituted by $\mathrm{Cu} / \mathrm{Zn}$-dependent enzymes, which protect the placenta from any undue harm. Serum or placental Zn concentrations have been reported to be low in early pregnancy women ${ }^{27}$ and was similar in the present study. Maternal zinc deficiency can lead to an adverse pregnancy outcome, such as intrauterine growth retardation due to reduced estrogen and zinc binding protein levels. ${ }^{28}$ According to earlier study placental metallothionein like GSH might play a protective role against cadmium toxicity by its binding to the metals. ${ }^{23}$ The level of placental $\mathrm{Zn}$ and $\mathrm{Cu}$ were found higher in full-term groups than pre-term groups. $\mathrm{Cu}$ and $\mathrm{Zn}$ are main cofactor enzyme of GSH, thus increased level of GSH was found in full-term delivery compared to pre-term delivery (Figure $1 \mathrm{~b}$ ) indicate oxidative stress inhibited by GSH, whereas the difference between $\mathrm{Zn}$ and $\mathrm{Cu}$ with GSH were not found statistically significant. Higher concentration of $\mathrm{Zn}$ and $\mathrm{Cu}$ in placental tissue of women with full-term deliveries may be shielding against oxidative stress in full- term, thus making the, the antioxidant defence system indirectly proportional to oxidative stress as observed in the present study.

About placental haemoglobin concentration, the level of haemoglobin was lower in pre-term groups than fullterm groups. The difference between blood haemoglobin was found statistically significant $(p<0.001)$ in pre-term delivery. Its fact, $\mathrm{Fe}$ is an essential constituent of heme in blood, when Fe levels are low, as reported in our study, it may lead to decreased haemoglobin synthesis and statistically significant of blood haemoglobin may be implicated in early pregnancy. A possible explanation for the reduced content of $\mathrm{Fe}$ in the placenta of the women with pre-term delivery may be related to elevated levels of $\mathrm{Cd}$ and $\mathrm{Pb}$ found in the placenta of the women with pre-term in our study. This condition may the disruption of placenta Fe homeostasis and lead to premature birth. ${ }^{29}$ A possible association between iron deficiency and excess with free radical mitochondrial damage, results oxidative stress is agreement with previous report. ${ }^{30}$ An earlier study reported that the increased $\mathrm{Pb}$ level affects the essential metal level and its level increased with parity (number of children) whereas, there was a depletion of maternal stores of essential elements ( $\mathrm{Zn}, \mathrm{Cu}$ and $\mathrm{Fe}$ ) with increasing parity. ${ }^{14}$ Deficiency in level of $\mathrm{Zn}$ has been identified as a risk factor for maternal anemia has been determined. ${ }^{31} \mathrm{In}$ our study, level of $\mathrm{Zn}$ was found lower in preterm delivery may be concerned in anemia. According to a previous study, in maternal anemia, placental copper is not a forecaster, but significant copper deficiency has been observed in pregnant women with anemia. Deficiency of iron during pregnancy conducing to anemia and about $90 \%$ of anemia cases have reported in India that can have deleterious effects on mother and as well as fetus in the form of poor weight gain and preterm delivery. ${ }^{32}$ Given that a low status of essential metals may raise the hazardous effect of lead and cadmium in placenta could be one of primary risk factor of preterm delivery. ${ }^{33}$ In our study, diminished level of essential metals $(\mathrm{Zn}, \mathrm{Cu}, \mathrm{Fe})$ and increased concentration of toxic metals $(\mathrm{Pb}, \mathrm{Cd})$ in study group may be associated with modulate the redox status in placental tissue. As expected, an interrelationship between increased levels of toxic metals, MDA and decreased essential metals, GSH levels in placenta, which may be coupled to preterm delivery.

\section{CONCLUSION}

The results of this study revealed that disturbance in levels of essential/toxic metals is related to unnecessary elevated level of oxidative stress and diminished the protective mechanisms such as GSH could be part of the pre-term deliveries. Significantly elevated levels of $\mathrm{Pb}$ and $\mathrm{Cd}$ were significantly correlated with MDA, suggests toxic metalsinduced pre-term delivery in women of the present study through the altered the oxidant/antioxidants status in placental tissue. Future research should be directed at confirming the free radical mechanism of metals- induced pre-term delivery as observed in present study and needed to develop strategies to prevent the increased levels of toxic metals in pregnant women.

\section{ACKNOWLEDGMENTS}

One of the authors, Madhu Anand, gratefully acknowledge Dr D S Kothari post doctoral fellowship (F. 4-2/2006(BSR)/13-556/2011(BSR)) by the University Grants Commissions, New Delhi, Government of India and Laxmi Singh also thankful to Societal of Research Fellowship "Disha” (DST/Disha/SoRF-PM/025/2013).

\section{REFERENCES}

1. Banerjee BD, Mustafa MD, Sharma T, Tyagi V, Ahmed RS, Tripathi AK, et al. Assessment of toxicogenomic risk factors in etiology of preterm delivery. Reprod Syst Sex Disord 2014; 3:5-10.

2. Nandan D, Mishra SK, Jain M, Singh D, Verma M and Sethi V. Social audit for community actions: A tool to initiate community action for reducing child mortality. Indian $\mathrm{J}$ Community Med 2005; 30:78-80.

3. Report of USAID-EHP Urban Health Program. Draft Summary Situational Analysis. Report of Agra City for Guiding Urban Health Program 2009. 
4. Farhang L, Weintraub JM, Petreas M, Eskenazi B and Bhatia R. Association of DDT and DDE with birth Weight and length of Gestation in the child health and development studies 19591967. Am J Epidermiol 2005; 162:717-725.

5. Zheng J. Recent advances in research on the Human Placenta, $1^{\text {st }}$ edition, Croatia, InTech 2012.

6. Al-Saleha I, Shinwaria N, Mashhoura A, El Din Mohamedb J and Rabahc A. Heavy metals (lead, cadmium and mercury) in maternal, cord blood and placenta of healthy women. Int J Hyg and Environ Health 2011; 214:79-101.

7. Myatt $L$ and Cui $X$. Oxidative stress in the placenta. Histochem Cell Biol 2004; 122:369-382.

8. Lappas M. N-Acetyl-cysteine inhibits phospholipid metabolism, proinflammatory cytokine release, protease activity, and nuclear factor-kappaB deoxyribonucleic acid-binding activity in human fetal membranes in vitro. J Clin Endocrinol Metab 2003; 88: 1723-1729.

9. Bayhan G, Atamer A, Yokus B and Baylan, Y. Significance of changes in lipid peroxidation and antioxidant enzymes activities in pregnant women with preeclampsia and eclampsia. Clin Exp Obstet Gynecol 2000; 27:142-146.

10. Miguel $N$, Ana $L$ and Ronco $M$. Fetal growth restriction is related to placental levels of cadmium, lead and arsenic but not with antioxidant activities. Reprod Toxicol 2009; 27:88-92.

11. Osman K, Akesson A, Berglund M, Bremme K, Schutz A, Ask $\mathrm{K}$, et al. Toxic and essential elements in placentas of Swedish women. Clin Biochem 2000; 33:131-138.

12. Ohkawa $\mathrm{H}$, Ohishi $\mathrm{N}$ and Yagi $\mathrm{K}$. Assay for lipid peroxides in animal tissues by thiobarbituric acid reaction. Anal Biochem 1979; 95: 351-358.

13. Ellman GL. Tissue sulfhydryl groups. Arch Bioachm Biophys 1959; 82:70-74.

14. Singh J, Singh VK, Anand M, Kumar $P$ and Siddiqui MKJ. Placental Lead and its Interaction with Some Essential Metals among Women from Lucknow, India. Asian Journal of Medical Sciences 2010; 1:32-36.

15. Poston L and Raijmakers MTM. Trophoblast oxidative stress, antioxidants and pregnancy Outcome-A review. Placenta 2004; 25:572-578.

16. DiSilvestro RA. Zinc in relation to diabetes and oxidative disease. J Nutr 2000; 130: 1509-1511.

17. Zadrozna M, Gawlik M, Nowak B, Marcinek A, Mrowiec H, Walas $S$, et al. Antioxidants activities and concentration of selenium, zinc and copper in preterm and IUGR human placentas. J Trace Elem Med Biol 2009; 23:144-148.

18. Chakravartya S and Sontakkeb AN. A correlation of antioxidants and lipid peroxidation between maternal and cord blood in full term and preterm deliveries. Curr Pediatr Res 2012; 16:167-174.

19. Joseph P. Mechanisms of cadmium carcinogenesis. Toxicol Appl
Pharmacol 2009; 238: 272-279.

20. Masso EL and Corredor L, Antonio MT. Oxidative damage in liver after perinatal intoxication with lead and/or cadmium. J Trace Elem Med Biol 2007; 21:210-216.

21. Falcon $M$, Vinas $P$ and Luna $A$. Placental lead and outcome of pregnancy. Toxicology 2003; 185:59-66.

22. Kim YJ, Hong YC, Lee KH, Park HJ, Park EA, Moon HS, et al. Oxidative stress in pregnant women and birth weight reduction. Reprod Toxicol 2005; 19:487-492.

23. Cuypers $A$, Plusquin $M$, Remans $T$, Jozefczak $M$, Keunen $\mathrm{E}$, Gielen $\mathrm{H}$, et al. Cadmium stress: An oxidative challenge. Biometals 2010; 23:927-940.

24. Kippler M, Hoque AM, Raqib R, Öhrvik H, Ekström EC and Vahter M. Accumulation of cadmium in human placenta interacts with the transport of micronutrients to the fetus. Toxicol Lett 2010; 192:162-168.

25. Kumar A, Singh L, Tanveer S and Taneja A. Concentration of heavy metals and dissipation pattern of particulate pollutant on burning of different biomass fuels. Indian J Environ Prot 2012; 32:829-833.

26. Ahamed $M$, Mehrotra PK, Kumar $P$ and Siddiqui MKJ Placental lead-induced oxidative stress and preterm delivery. Environmental Toxicology and Pharmacology 2009; 27:70-74.

27. Kolusari A, Kurdoglu M, Yildizhan R, Adali E, Edirne T, Cebi A, et al. Catalase Activity, Serum Trace Element and Heavy Metal Concentrations, and Vitamin A, D and E Levels in PreEclampsia. The Journal of International Medical Research 2008; 36:1335-1341.

28. Bassiouni BA, Foda Al and Rafai AA. Maternal and fetal plasma zinc in preeclampsia. Eur J Obstet Gynecol Rprod Biol 1979; 9:75-80.

29. Ronco AM, Arguello G, Munoz L, Gras N and Llanos MN. Metals content in placentas from moderate cigarette consumers, correlation with newborn birth weight. Biometals 2005; 18:233-241.

30. Liochev SI and Friedovich I. How does superoxide dismutase protect against tumor necrosis factor: A hypothesis informed by effect of superoxide on "free" iron. Free Radic Biol Med 1997; 23:668-671.

31. Abdelrahim II, Mahgoub HM, Mohamed AA, Ali NI, Elbashir MI and Adam I. Anaemia, folate, zinc and copper deficiencies among adolescent schoolgirls in eastern Sudan. Biol Trace Elem Res 2009; 132:60-66.

32. Bushra M, Elhassan EM, Ali NI, Osman E, Bakheit $\mathrm{KH}$ and Adam II. Anaemia, zinc and copper deficiencies among pregnant women in central Sudan. Biol Trace Elem Res 2010; 137:255-261.

33. Goyer RA. Toxic and essential metal interactions. Ann Rev Nutr 1997; 17: 37-50.

Authors Contribution:

LS - Concept and design of the study, statistically analyzed and interpreted data, reviewed the literature, manuscript preparation and critical revision of the manuscript; PA - Collected data and samples from hospital, helped in laboratory analysis of samples; MA - Conceptualized study, helped in preparing first draft of manuscript with statistically analysis and critical revision of the manuscript; AT - Concept of study, and critical revision of the manuscript.

Source of Support: Funds for this work is provided by Dr D S Kothari post doctoral fellowship (F. 4-2/2006(BSR)/13-556/2011(BSR)) by the UGC, New Delhi, Government of India and by DST project of SoRF "Disha” (DST/Disha/SoRF-PM/025/2013), Conflict of Interest: None declared. 